\title{
Phase stability of hafnium oxide and zirconium oxide on silicon substrate
}

\author{
Dongwon Shin*, Zi-Kui Liu \\ Department of Materials Science and Engineering, \\ The Pennsylvania State University, University Park, PA 16802, USA
}

\begin{abstract}
Phase stabilities of Hf-Si-O and Zr-Si-O have been studied with first-principles and thermodynamic modeling. From the obtained thermodynamic descriptions, phase diagrams pertinent to thin film processing were calculated. We found that the relative stability of the metal silicates with respect to their binary oxides plays a critical role in silicide formation. It was observed that both the $\mathrm{HfO}_{2} / \mathrm{Si}$ and $\mathrm{ZrO}_{2} / \mathrm{Si}$ interfaces are stable in a wide temperature range and silicide may form at low temperatures, partially at the $\mathrm{HfO}_{2} / \mathrm{Si}$ interface.

(C) 2018 Elsevier Ltd. All rights reserved.

thin films; Silicides; thermodynamics; CALPHAD; first-principle electron theory
\end{abstract}

The thickness of $\mathrm{SiO}_{2}$ as a gate oxide material in advanced complementary metal oxide semiconductor (CMOS) integrated circuits has continuously decreased and reached the current processing limits[1]. Alternative materials with higher dielectric constants, such as $\mathrm{HfO}_{2}$ and $\mathrm{ZrO}_{2}$, are considered as candidates to replace $\mathrm{SiO}_{2}$ for further improvement of their performance[2]. However, during the thin film deposition or the subsequent rapid thermal annealing, oxides, silicates, and silicides may form at the interface since most high- $k$ materials are metal oxides $[3,4]$. Among those interfacial phases, silicides are detrimental to capacitor performance due to their metallic behavior[5]. In this regard, thermodynamic stability calculations and experimental results have shown that the interface between $\mathrm{HfO}_{2}$ and $\mathrm{Si}$ is found to be stable with respect to the formation of silicides[4]. On the other hand, the $\mathrm{ZrO}_{2} / \mathrm{Si}$ interface was found to be unstable around $1000 \mathrm{~K}$, which is in contradiction to the calculation by Hubbard and Schlom [2]. It was also observed that the Hf-silicide forms upon decomposition of $\mathrm{HfO}_{2}$ in low oxygen partial pressures $[5,6,7,8]$ and $\mathrm{HfSiO}_{4}$ suppresses Hf-silicide formation [9].

Although the phase stabilities in the Hf-Si-O and $\mathrm{Zr}-\mathrm{Si}$ $\mathrm{O}$ systems are important, comprehensive thermodynamic explanations are not yet available. In this paper, based on the recently developed thermodynamic descriptions of the Hf-Si-O $[10]$ and Zr-Si-O systems with first-principles calculations and thermodynamic CALculation of PHAse Dia-

\footnotetext{
* Corresponding author. Corresponding author.

Email address: dus136@psu.edu (Dongwon Shin).
}

grams (CALPHAD)modeling[11], various phase diagrams pertinent to thin film processing are investigated.

In the CALPHAD approach, the Gibbs energies of individual phases in a system are evaluated from the existing experimental data with the so-called sublattice model based on the crystal structures. The Gibbs energies of a higher-order system can be readily extrapolated from the lower-order systems, and any new phases of the higherorder system can be introduced. However, it is not always possible to have enough experimental data for thermodynamic modeling of a system[2] so that theoretical calculations, such as first-principles calculation results, can be used as supplementary experimental data. The Hf-Si-O system was recently modeled with first-principles calculations and the CALPHAD approach[10]. The formation enthalpy for $\mathrm{HfSiO}_{4}$ is calculated from first-principles calculations since no experimental measurement is reported. The reference states of the formation enthalpy for $\mathrm{HfSiO}_{4}$ are derived from the two binary metal oxides as shown in Eqn. 1, where $E$ represents the total energy of each phase. The formation entropy of $\mathrm{HfSiO}_{4}$ was evaluated from the temperature of peritectic reaction, $\mathrm{HfO}_{2}+$ Liquid $\rightarrow \mathrm{HfSiO}_{4}$, in the $\mathrm{HfO}_{2}-\mathrm{SiO}_{2}$ pseudo-binary system. The thermodynamic description of the Zr-Si-O system was obtained by combining the previous modelings[12, 13, 14] and first-principles calculation of $\mathrm{ZrSiO}_{4}$ in the present work.

$$
\Delta H_{f}^{\mathrm{HfSiO}_{4}}=E\left(\mathrm{HfSiO}_{4}\right)-\frac{1}{2} E\left(\mathrm{HfO}_{2}\right)-\frac{1}{2} E\left(\mathrm{SiO}_{2}\right)
$$

The highly efficient Vienna $A b$ initio Simulation Package (VASP) [15] was used to perform the density functional theory (DFT) electronic structure calculations. The projector 
augmented wave (PAW) method[16] was chosen, and the generalized gradient approximation (GGA)[17] was used to take into account exchange and correlation contributions. An energy cutoff was constantly set as $500 \mathrm{eV}$ for all the structures, and the Monkhorst-Pack scheme was used for the Brillouin-zone integrations. For the $k$-point sampling, authors aimed all the structures to have the $k$-point meshes as close as (\# of atoms in a structure) $\times k_{x} \times k_{y} \times k_{z} \simeq$ $5000 k$-points. Thus, $\mathrm{HfSiO}_{4}$ and $\mathrm{ZrSiO}_{4}$, for example, have $8 \times 8 \times 8 k$-point meshes. The calculated results of metal oxides and silicates are listed in Table 1.

From the constructed thermodynamic databases of the $\mathrm{Hf}-\mathrm{Si}-\mathrm{O}$ and $\mathrm{Zr}-\mathrm{Si}-\mathrm{O}$ systems, the isopleths of $\mathrm{HfO}_{2}-\mathrm{Si}$ and $\mathrm{ZrO}_{2}$-Si are calculated in order to investigate the stability range of silicides at the metal oxides/silicon interface and are given in Figure 1. Calculated results show that $\mathrm{HfSi}_{2}$ is stable up to $544 \mathrm{~K}$ based on the formation enthalpy of $\mathrm{HfSiO}_{4}$ from first-principles calculations. It is generally accepted that the uncertainty of the formation enthalpy of intermetallic compounds, which originates from the density functional theory itself, is about $\pm 1 \mathrm{~kJ} /$ mol-atom[18, 19]. Thus the associated decomposition temperature of $\mathrm{HfSi}_{2}$ at the $\mathrm{HfO}_{2} / \mathrm{Si}$ interface ranges from 382 to $670 \mathrm{~K}$ when the formation enthalpy of $\mathrm{HfSiO}_{4}$ is adjusted within its uncertainty range from -0.769 to $-2.769 \mathrm{~kJ} / \mathrm{mol}$-atom. The formation entropy of $\mathrm{HfSiO}_{4}$ with respect to the binary oxides was evaluated correspondingly to reproduce its peritectic reaction at $2023 \mathrm{~K}$. It should be noted that the phase stability range of $\mathrm{HfSi}_{2}$ in the $\mathrm{HfO}_{2}$-Si isopleth is not directly correlated with the first-principles calculation of $\mathrm{HfSiO}_{4}$, but predicted from the Gibbs energies of other phases, including the $\mathrm{HfSiO}_{4}$ phase, in the Hf-Si-O system. Even with the uncertainty of formation enthalpy for $\mathrm{HfSiO}_{4}$, the temperature range for the $\mathrm{HfO}_{2}$ and $\mathrm{Si}$ coexistent phase region in the isopleth is fairly wide from 670 to $1700 \mathrm{~K}$.

For $\mathrm{ZrSiO}_{4}$, besides the uncertainty of formation enthalpy from first-principles in the present work, the peritectic reaction $\left(\mathrm{ZrO}_{2}+\right.$ Liquid $\left.\rightarrow \mathrm{ZrSiO}_{4}\right)$ temperature in the $\mathrm{ZrO}_{2}-\mathrm{SiO}_{2}$ pseudo-binary is also uncertain from 1910 to $1949 \mathrm{~K}$. Thus, the formation entropy of $\mathrm{ZrSiO}_{4}$ varies accordingly. The Gibbs energy of $\mathrm{ZrSiO}_{4}$ at $1000 \mathrm{~K}$ evaluated from the formation enthalpy derived from first-principles and formation entropy evaluated from the peritectic temperature of $1949 \mathrm{~K}$ (listed in Table 1) is almost identical to the value used by Hubbard and Schlom [2]. With these formation enthalpy and entropy values of $\mathrm{ZrSiO}_{4}, \mathrm{ZrSi}_{2}$ is completely suppressed by $\mathrm{ZrSiO}_{4}$ and does not show up in the $\mathrm{ZrO}_{2}-\mathrm{Si}$ isopleth. To make $\mathrm{ZrSi}_{2}$ appear in the $\mathrm{ZrO}_{2}-\mathrm{Si}$ isopleth, the formation enthalpy of $\mathrm{ZrSiO}_{4}$ should be more negative than the first-principles calculation result within the uncertainty of formation enthalpy and peritectic temperature for $\mathrm{ZrSiO}_{4}$. When formation enthalpy of $\mathrm{ZrSiO}_{4}$ with respect to the binary metal oxides is set to its lowest limit from the uncertainty of first-principles calculations, $\Delta H_{f}^{\mathrm{ZrSiO}_{4}}=-3.358 \mathrm{~kJ} / \mathrm{mol}$-atom, and entropy of formation is evaluated as $\Delta S_{f}^{\mathrm{ZrSiO}_{4}}=0.788 \mathrm{~J} / \mathrm{mol}$-atom $\cdot \mathrm{K}, \mathrm{ZrSi}_{2}$ is stable up to $879 \mathrm{~K}$ in the $\mathrm{ZrO}_{2}-\mathrm{Si}$ isopleth. Then formation enthalpy of $\mathrm{ZrSiO}_{4}$ is $\Delta H_{f}^{\mathrm{ZrSiO}_{4}}=-338.568 \mathrm{~kJ} / \mathrm{mol}-$ atom with respect to SER (Standard Element Reference) and this agrees well with the experimental measurement, $-339.033 \mathrm{~kJ} / \mathrm{mol}$-atom from Ellison and Navrotsky [20]. Consequently, the safe temperature range for $\mathrm{ZrO}_{2}$ to be stable with $\mathrm{Si}$ is between 879 and $1630 \mathrm{~K}$, narrower than that of $\mathrm{HfO}_{2}$ and $\mathrm{Si}$. However, even with these uncertainties, both metal oxides are stable with $\mathrm{Si}$ approximately above 900K as summarized by Hubbard and Schlom [2](1000K).

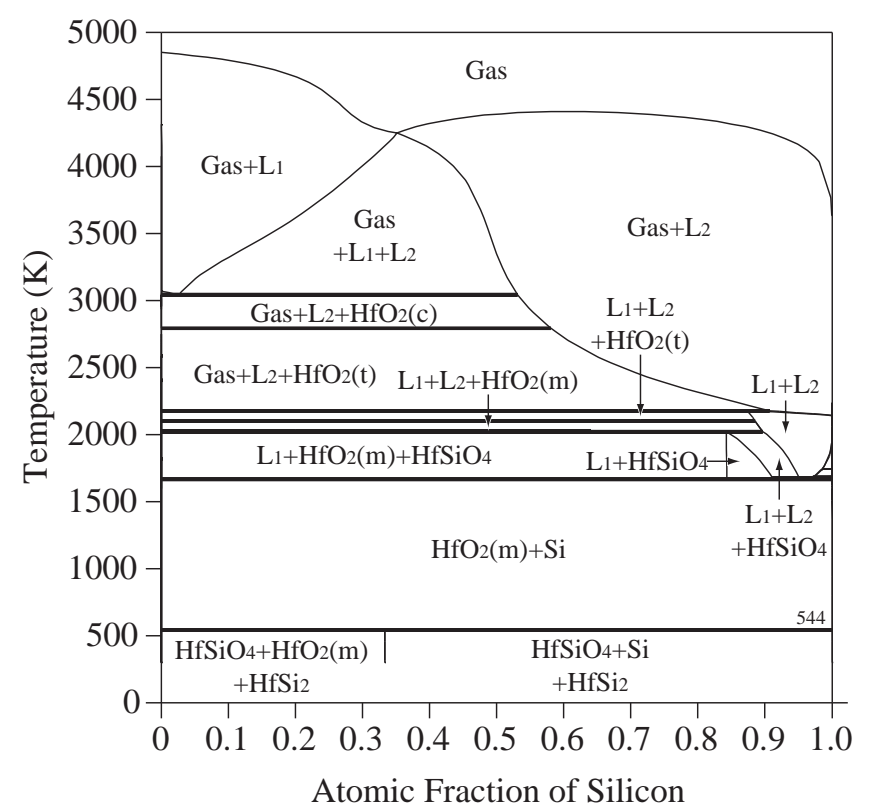

(a) Isopleth of $\mathrm{HfO}_{2}$ and $\mathrm{Si}$

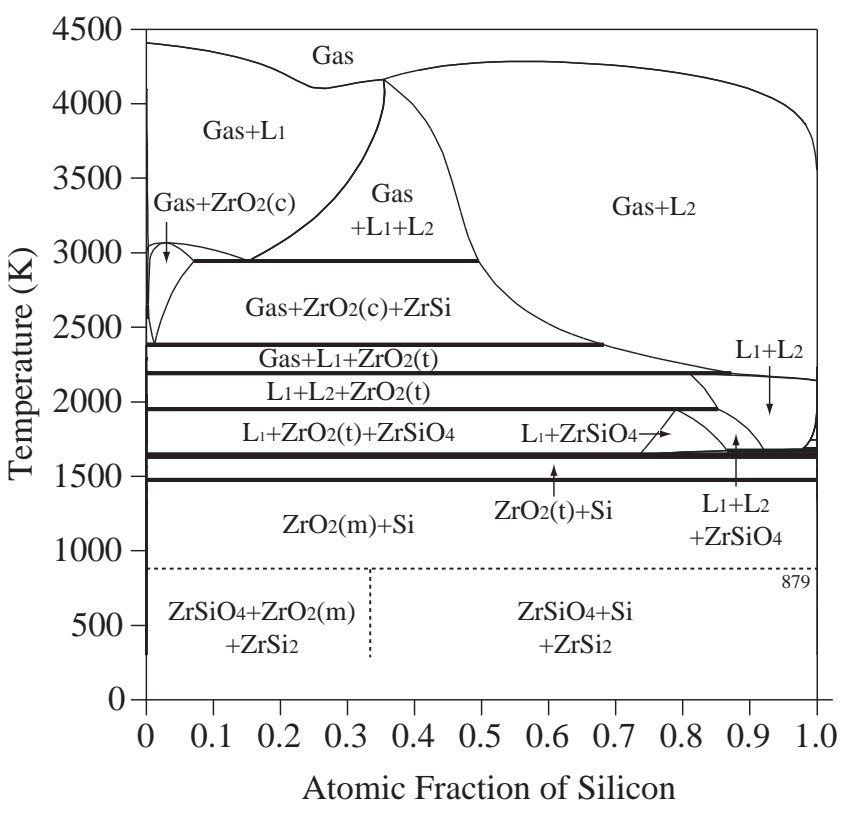

(b) Isopleth of $\mathrm{ZrO}_{2}$ and $\mathrm{Si}$

Fig. 1. Calculated isopleths of $\mathrm{HfO}_{2}-\mathrm{Si}$ and $\mathrm{ZrO}_{2}-\mathrm{Si}$ at 1 atm. Polymorphs of metal oxides for $\mathrm{HfO}_{2}$ and $\mathrm{ZrO}_{2}$, i.e. monoclinic, tetragonal, and cubic, are given in parentheses.

These isopleth calculation results are in agreements with 
Table 1

First-principles calculation results of metal oxides and metal silicates.

\begin{tabular}{|c|c|c|c|c|c|c|c|c|c|c|}
\hline \multirow[t]{2}{*}{ Phases } & \multicolumn{2}{|l|}{ Space } & \multicolumn{5}{|c|}{ Lattice parameters } & \multirow{2}{*}{$\begin{array}{r}\text { Total energy } \\
(\mathrm{eV} / \text { atom })\end{array}$} & \multirow[t]{2}{*}{$\Delta H_{f}^{a}$} & \multirow{2}{*}{$\begin{array}{c}\Delta S_{f}^{a, b} \\
\mathrm{~J} / \mathrm{mol} \text {-atom } \cdot \mathrm{K}\end{array}$} \\
\hline & Group & $\mathrm{a}$ & $\mathrm{b}$ & $\mathrm{c}$ & $\alpha$ & $\beta$ & $\gamma$ & & & \\
\hline $\mathrm{HfO}_{2}$ & $P 2_{1} / c$ & 5.13 & 5.194 & 5.314 & 909 & 99.56 & 90 & -10.2101 & - & $\begin{array}{ll}- & \text { - }\end{array}$ \\
\hline $\mathrm{ZrO}_{2}$ & $P 2_{1} / c$ & 5.221 & 5.287 & 5.398 & 909 & 99.63 & 90 & -9.5376 & $\begin{array}{ll}- & - \\
\end{array}$ & - \\
\hline $\mathrm{SiO}_{2}$ & $P 3_{2} 21$ & $5.00^{7}$ & 5.007 & 5.496 & 90 & 90 & 120 & -7.9581 & - & - \\
\hline $\mathrm{HfSiO}_{4}$ & $I 4_{1} / a$ & .61 & 61 & U & & 90 & 90 & -9.1024 & -1.769 & -0.219 \\
\hline $\mathrm{ZrSiO}_{4}$ & $I 4_{1} / a m$ & 6.698 & 6.698 & 6.038 & & 90 & 90 & -8.7723 & -2.358 & -0.275 \\
\hline
\end{tabular}

${ }^{a}$ Formation enthalpies and entropies of metal silicates are expressed with respect to their binary oxides.

b Formation entropies are evaluated from temperature of peritectic reactions $\left(M \mathrm{O}_{2}+\right.$ Liquid $\left.\rightarrow M \mathrm{SiO}_{4}\right)$.

Gutowski et al. [4] for the Hf-Si-O system but not with the Zr-Si-O system. In their calculations, they assumed that thermal effects are of secondary importance for Gibbs energy change so that the contribution from entropy was ignored in the calculations for silicide formation reactions. However, our calculations from the individual thermodynamic databases showed that such an entropy effect cannot be neglected. According to our calculation results, both $\mathrm{HfO}_{2}$ and $\mathrm{ZrO}_{2}$ are stable with $\mathrm{Si}$ and this is in agreement with the calculation from Hubbard and Schlom [2]. However, $\mathrm{ZrSi}_{2}$ was found at the metal oxide/Si interface in their experiment[4] while $\mathrm{HfO}_{2}$ was stable on $\mathrm{Si}$ without any silicides formation when they deposited at $823 \mathrm{~K}$ and then annealed at $1073 \mathrm{~K}$. It can be explained that since their fabrication process was rapid thermal chemical-vapor deposition (RTCVD), it might not have reached the thermodynamic equilibrium state. Furthermore, the oxygen partial pressure of their experiment was not reported. The effect of oxygen partial pressure will be discussed later in this paper.

The calculated isopleths indicate that metal silicates play an important role in the silicide formation as suggested by Takahashi et al. [9] From first-principles calculations, the formation enthalpy of $\mathrm{ZrSiO}_{4}$ is $-2.358 \pm 1 \mathrm{~kJ} / \mathrm{mol}$-atom whereas that of $\mathrm{HfSiO}_{4}$ is only $-1.769 \pm 1 \mathrm{~kJ} / \mathrm{mol}$-atom when the reference states are set to the binary oxides. It is intriguing to see that such a small $(0.6 \mathrm{~kJ} / \mathrm{mol}$-atom $)$ difference in the formation of metal silicates greatly affects the phase stability at the metal oxides/silicon interface. This can be explained by comparing the relationship between metal oxides, silicates, and silicides in the isothermal section.

Isothermal sections of the $\mathrm{Zr}-\mathrm{Si}-\mathrm{O}$ system at two different temperatures, $500 \mathrm{~K}$ and $1000 \mathrm{~K}$, are calculated (see Figure 2) to investigate the phase relationship regarding the decomposition of $\mathrm{ZrSi}_{2}$ at the $\mathrm{ZrO}_{2} / \mathrm{Si}$ interface. The two different three-phase regions, $\mathrm{ZrSiO}_{4}+\mathrm{ZrO}_{2}+\mathrm{ZrSi}_{2}$ and $\mathrm{ZrSiO}_{4}+\mathrm{ZrSi}_{2}+\mathrm{Si}$, in the $500 \mathrm{~K}$ isothermal section are intersected by the line connecting $\mathrm{ZrO}_{2}$ and $\mathrm{Si}$. Therefore, $\mathrm{ZrSi}_{2}$ can be found in the thin film process. However, the $1000 \mathrm{~K}$ calculation shows that $\mathrm{ZrO}_{2}$ is stable with the $\mathrm{Si}$ substrate without any silicide formation as there is a tie line connecting $\mathrm{ZrO}_{2}$ and $\mathrm{Si}$. Isothermal sections of Hf-Si-O at the same temperatures, $500 \mathrm{~K}$ and $1000 \mathrm{~K}$, showed similar phase stabilities as Zr-Si-O[10].

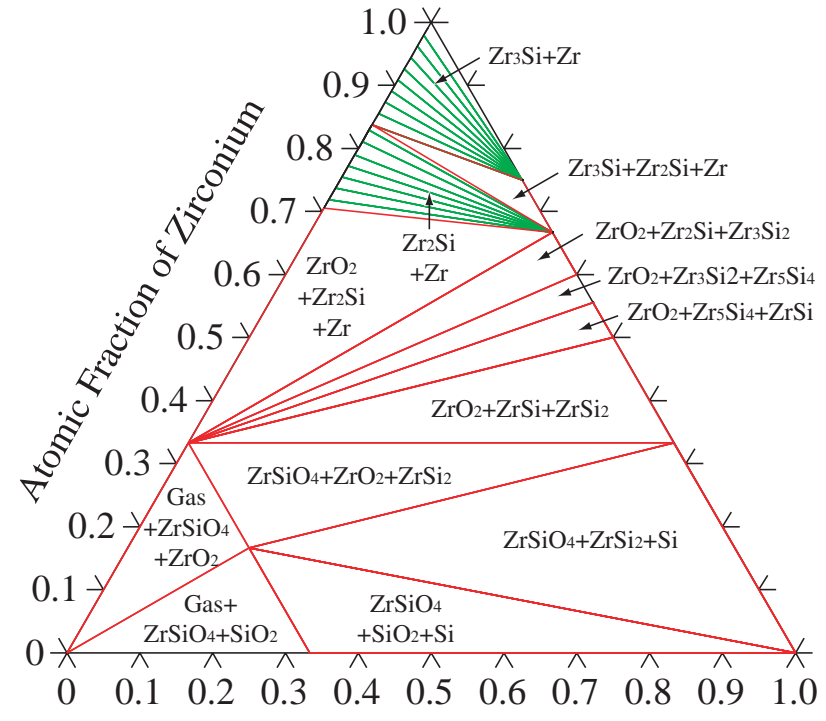

Atomic Fraction of Silicon

(a) $\mathrm{Zr}-\mathrm{Si}-\mathrm{O}$ at $500 \mathrm{~K}$

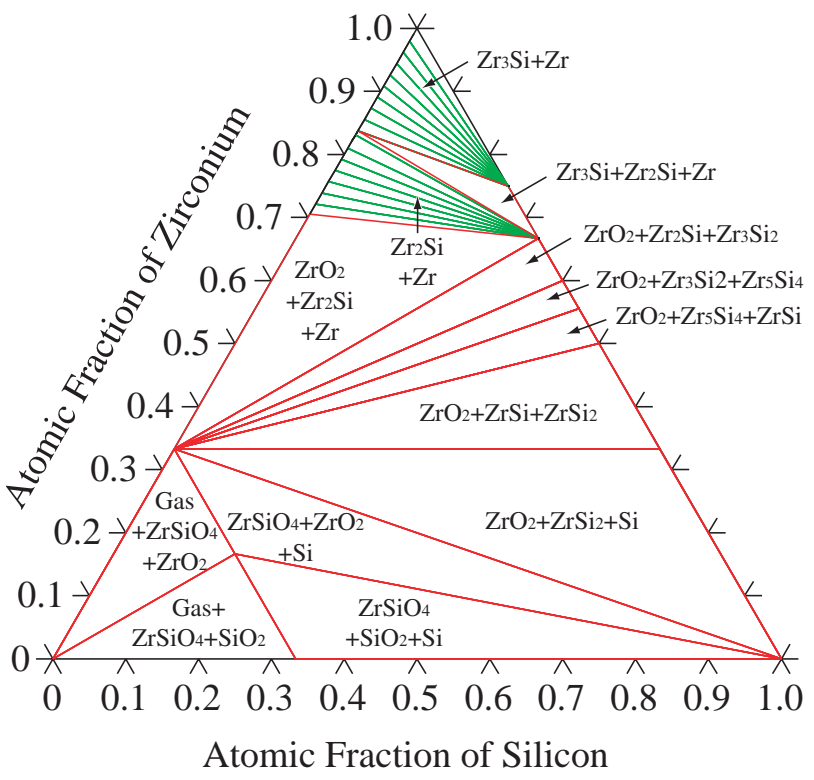

(b) $\mathrm{Zr}-\mathrm{Si}-\mathrm{O}$ at $1000 \mathrm{~K}$

Fig. 2. Calculated isothermal sections of $\mathrm{Zr}-\mathrm{Si}-\mathrm{O}$ at (a) $500 \mathrm{~K}$ and (b) $1000 \mathrm{~K}$. Tie lines are drawn inside the two phase regions.

According to the calculation results of isopleths and isothermal sections of the $\mathrm{Hf}-\mathrm{Si}-\mathrm{O}$ system, $\mathrm{HfO}_{2}$ and $\mathrm{Si}$ 
should be stable at the temperature range between $670 \mathrm{~K}$ and $1700 \mathrm{~K}$. However, it is reported that under oxygendeficient conditions, Hf-silicide forms at the $\mathrm{HfO}_{2} / \mathrm{Si}$ interface even in this temperature range. Wang et al. [6] found that oxygen-deficient $\mathrm{HfO}_{x<2}$ consumes the oxygen in the $\mathrm{SiO}_{2}$ thin layer covered on the silicon substrate to form fully oxidized metal oxide. Even the layer of silicates will be decomposed along with the progress of $\mathrm{HfO}_{x<2}$ deposition. The recent work from Miyata et al. [7] also confirmed the formation of nanometer-scale $\mathrm{HfSi}_{2}$ dots on the newly opened void surface produced by the decomposition of $\mathrm{HfO}_{2} / \mathrm{SiO}_{2}$ films at the oxide/void boundary in vacuum.

To further understand the effect of the oxygen partial pressure, the phase diagrams of oxygen partial pressuretemperature are calculated and shown in Figure 3 with the ratio between the metals ( $\mathrm{Hf}$ and $\mathrm{Zr}$ ) and $\mathrm{Si}$ set to 1 . It should be mentioned here that the oxygen partial pressure in these calculations are the local oxygen pressure at the interface, which is extremely low. Consequently, both systems initially form only metallic silicides. As oxygen partial pressure increases, part of the silicides transform into metal oxides. Afterwards, $\mathrm{HfO}_{2}$ and $\mathrm{Si}$ are stable in the HfSi-O system as confirmed by experiments. $[5,6,7,8]$ Then, $\mathrm{HfO}_{2}$ is in equilibrium with $\mathrm{HfSiO}_{4}$. In the Zr-Si-O system, with further oxidization, $\mathrm{ZrO}_{2}$ is stable with $\mathrm{Si}$. However, the phase region is narrower than that of the Hf-Si-O system. This is in agreement with Copel et al. [3] that $\mathrm{ZrO}_{2}$ is vulnerable to high temperature vacuum annealing. Therefore, it is possible to have a stable $\mathrm{ZrO}_{2} / \mathrm{Si}$ interface, but this is very challenging in the high vacuum condition.

In summary, with the thermodynamic descriptions of the Hf-Si-O and Zr-Si-O systems developed by the CALPHAD technique, isopleths and isothermal sections can be readily calculated. It is found that the $\mathrm{HfO}_{2} / \mathrm{Si}$ interface is thermodynamically stable between 670 and $1700 \mathrm{~K}$ as far as oxygen partial pressure is high enough to keep $\mathrm{HfO}_{2}$ stable. $\mathrm{ZrO}_{2} / \mathrm{Si}$ interface is stable between 879 and $1630 \mathrm{~K}$, but in the oxygen-deficient condition, the processing window for a stable $\mathrm{ZrO}_{2} / \mathrm{Si}$ interface is very narrow. Both metal oxides are stable with a Si substrate above $900 \mathrm{~K}$, even with the uncertainties of the formation enthalpies and entropies for metal silicates.

This work is funded by the National Science Foundation (NSF) through grants DMR-0205232 and 0510180. Firstprinciples calculations were carried out on the LION clusters at the Pennsylvania State University supported in part by the NSF grants (DMR-9983532, DMR-0122638, and DMR-0205232) and in part by the Materials Simulation Center and the Graduate Education and Research Services at the Pennsylvania State University.

\section{References}

[1] G. D. Wilk, R. M. Wallace, and J. M. Anthony. J. Appl. Phys., 89(10):5243-5275, 2001.

[2] K. J. Hubbard and D. G. Schlom. J. Mater. Res., 11 (11):2757-2776, 1996.

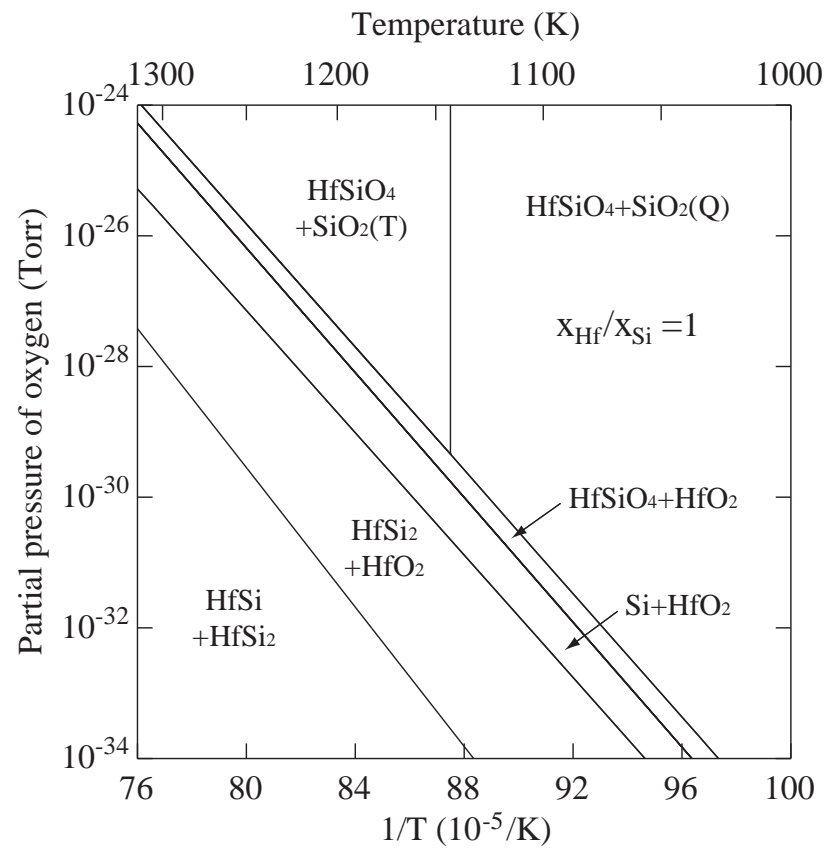

(a) $x_{\mathrm{Hf}} / x_{\mathrm{Si}}=1$

Temperature $(\mathrm{K})$

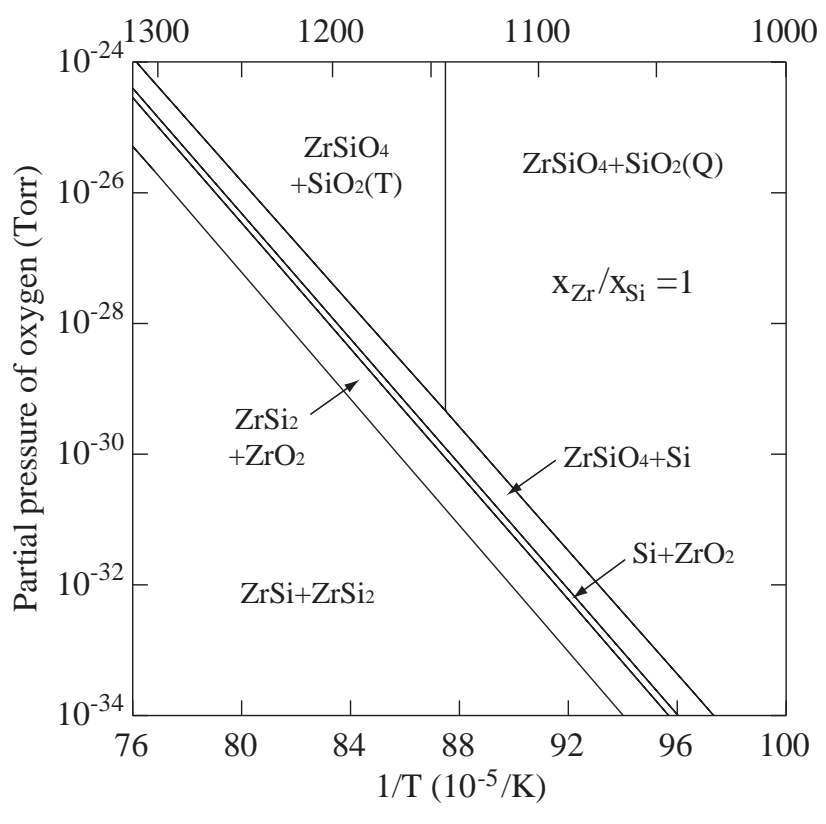

(b) $x_{\mathrm{Zr}} / x_{\mathrm{Si}}=1$

Fig. 3. Partial pressure of oxygen vs. temperature phase diagrams for (a) Hf-Si-O and (b) Zr-Si-O systems when $x_{\mathrm{Hf}, \mathrm{Zr}} / x_{\mathrm{Si}}=1 . \mathrm{SiO}_{2}(\mathrm{Q})$ and $\mathrm{SiO}_{2}(\mathrm{~T})$ represent Quartz and Tridymite, respectively.

[3] M. Copel, M. Gribelyuk, and E. Gusev. Appl. Phys. Lett., 76(4):436-438, 2000.

[4] M. Gutowski, J. E. Jaffe, C.-L. Liu, M. Stoker, R. I. Hegde, R. S. Rai, and P. J. Tobin. Appl. Phys. Lett., 80(11):1897-1899, 2002.

[5] D.-Y. Cho, K.-S. Park, B. H. Choi, S. J. Oh, Y. J. Chang, D. H. Kim, T. W. Noh, R. Jung, J.-C. Lee, and S. D. Bu. Appl. Phys. Lett., 86(4):041913/1-041913/3, 2005. 
[6] S. J. Wang, P. C. Lim, A. C. H. Huan, C. L. Liu, J. W. Chai, S. Y. Chow, J. S. Pan, Q. Li, and C. K. Ong. Appl. Phys. Lett., 82(13):2047-2049, 2003.

[7] N. Miyata, Y. Morita, T. Horikawa, T. Nabatame, M. Ichikawa, and A. Toriumi. Phys. Rev. B, 71(23): 233302/1-233302/4, 2005.

[8] H. Takahashi, S. Toyoda, J. Okabayashi, H. Kumigashira, M. Oshima, Y. Sugita, G. L. Liu, Z. Liu, and K. Usuda. Appl. Phys. Lett., 87(1):012903/1012903/3, 2005.

[9] H. Takahashi, S. Toyoda, J. Okabayashi, H. Kumigashira, M. Oshima, Y. Sugita, G. L. Liu, Z. Liu, and K. Usuda. Transactions of the Materials Research Society of Japan, 30(1):187-189, 2005.

[10] D. Shin, R. Arróyave, and Z.-K. Liu. CALPHAD, 30 (4):375-386, 2006.

[11] N. Saunders and A. P. Miodownik. CALPHAD (Calculation of Phase Diagrams): A Comprehensive Guide. Pergamon, Oxford, New York, 1998.

[12] B. Hallstedt. CALPHAD, 16(1):53-61, 1992.

[13] C. Gueneau, C. Servant, I. Ansara, and N. Dupin. CALPHAD, 18(3):319-27, 1994.

[14] C. Wang, M. Zinkevich, and F. Aldinger. CALPHAD, 28(3):281-292, 2005.

[15] G. Kresse and J. Furthmuller. Comput. Mater. Sci., 6 (1):15-50, 1996.

[16] G. Kresse and D. Joubert. Phys. Rev. B, 59(3):1758$1775,1999$.

[17] J. P. Perdew, J. A. Chevary, S. H. Vosko, K. A. Jackson, M. R. Pederson, D. J. Singh, and C. Fiolhais. Phys. Rev. B, 46(11):6671-87, 1992.

[18] C. Wolverton, X. Y. Yan, R. Vijayaraghavan, and V. Ozoliņš. Acta Mater., 50(9):2187-2197, 2002.

[19] S. G. Fries and T. Jantzen. Thermochim. Acta, 314 (1-2):23-33, 1998.

[20] A. J. G. Ellison and A. Navrotsky. J. Am. Ceram. Soc., 75(6):1430-1433, 1992. 